\title{
Design of Diapers Internal Environment Detection System
}

\author{
Dejun $\mathrm{Li}^{\mathrm{a}}$, Xiaobo $\mathrm{Lu}^{\mathrm{b}}$, Zheng Xie ${ }^{\mathrm{c}}$ \\ NO.1 Sunshine Avenue, Jiangxia district, Wuhan Textile University, Wuhan, Hubei Province, China \\ ald@@wtu.edu.cn, b1151999045@qq.com, '510819030@qq.com
}

Keywords: Diapers; Sensor; Smart Clothing.

\begin{abstract}
With the development of intelligent garment industry, the production of smart clothing is a sunrise industry. And the development of electronic information technology and clothing industry has brought great convenience to our life, it also has a vast market and applications. In this paper, we design a detection system of diaper environment that put four temperature sensors and one humidity sensor into different corners of the diaper wearable, the temperature sensors can be connected through analog-digital conversion with the single chip microcomputer and send the temperatures to the phone via Bluetooth on the single chip microcomputer. At the same time, the humidity sensor connects with the warning alarm of the phone to detect whether the baby pee to help us ensure the timely replacement of diapers and baby's health.
\end{abstract}

\section{Introduction}

Diapers is baby's daily necessities, the dry diapers can make the babes sleep well all night, and it is called "Diapers" due to its strong water absorption. In the application of diaper, it is a disposable goods that can be abandoned after being used. It is made by non-woven, toilet paper, hair paste, polymer absorbent polymer, PE film, rubber band and other materials. There are two kinds of diapers, one is for infants, and the other is for the adults. Good diapers generally have the following requirements: excellent absorb ability, dry and no leakage, moisture protective layer, leak proof design and the texture is soft, lightweight, breathable, tailored.

\section{Diaper Environmental Monitoring}

Fig 1 is the structure of the diapers. The humidity sensor is placed near where the child pees. Which is shown in the figure of the acquisition distribution layer, so that it is convenient for us in a timely manner to know whether the child pees, if the child pees, it will enable to trigger the alarm of the phone to ring. There are four temperature sensors, the first one is placed near the navel, which is shown in the figure of the magic buckle. As we all known, the navel is the weak part, need to pay attention to protect it and let the navel away from the cold. So it is necessary to check the temperature of the navel. The second one is placed near the magic stick which is on the figure. The magic stick is on the back of the body when the child wear the diapers, the temperature measurement near the back can help us to know whether the baby's cloths should be added or took off. The third one is placed near the place of the leakage proof, which can be coordinated with the humidity sensor, when the child pees, the temperature near the leakage proof can also be changed. The last one is placed near the acquisition distribution layer, which can also check the temperature when the child pees. The power and other equipment is packed together which can be dressed.

\section{Principle Features of the System}

Fig 2 is the framework of the diapers internal environment detection system. The system is based on the micro-controller as the core, temperature sensors and humidity sensor as the collection of temperature value and humidity value. In order to obtain a stable temperature and humidity values, protect the system away from the interference of the changeable environment, use the constant-current source as the driver, the data is transmitted to the micro-controller via the 
analog-to-digital conversion module. Then, the temperature values and the humidity value are sent to the phone by Bluetooth.

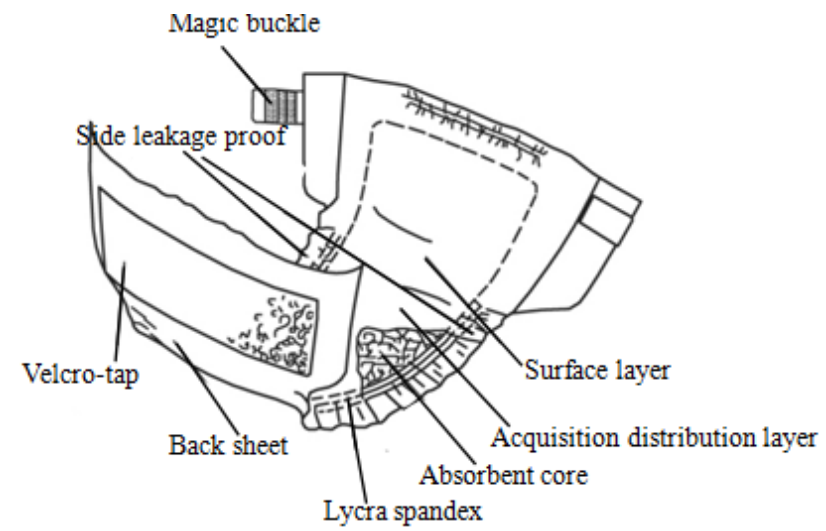

Fig 1. The structure of the diapers

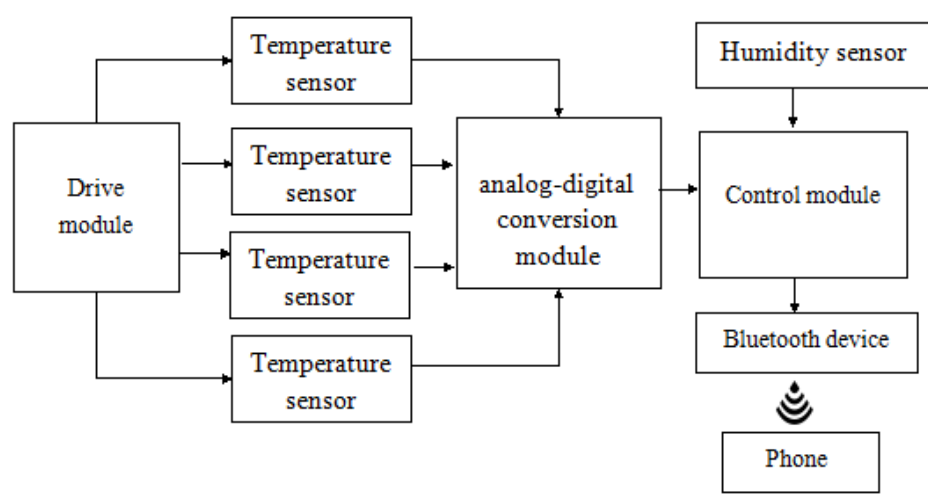

Fig 2. The Framework of the system

\subsection{The Choice of the Temperature Sensor.}

In order to match the design system, the choice of the temperature sensor is MF51-9.971K-3950-200L. Taking into account the diapers shape, and measure the temperature of different corners of the diapers, we select the two-wire sensor of the resistance, it is easy for us to place the sensors to where we want to put them in.

Taking into account the temperature of the human body, select the values form $0^{\circ} \mathrm{C}$ to $50^{\circ} \mathrm{C}$ of the sensor to operate. The parameters given by the manufacturer can be seen in Table 1 . It is about the relationship between temperature values and resistance values.

Table 1 . The parameters of the temperature sensor

\begin{tabular}{|l|l|l|l|l|l|l|l|l|l|}
\hline $\mathrm{T}\left({ }^{\circ} \mathrm{C}\right)$ & $\mathrm{R}(\mathrm{K} \Omega)$ & $\mathrm{T}\left({ }^{\mathrm{C}}\right)$ & $\mathrm{R}(\mathrm{K} \Omega)$ & $\mathrm{T}\left({ }^{\circ} \mathrm{C}\right)$ & $\mathrm{R}(\mathrm{K} \Omega)$ & $\mathrm{T}\left({ }^{\circ} \mathrm{C}\right)$ & $\mathrm{R}(\mathrm{K} \Omega)$ & $\mathrm{T}\left({ }^{\circ} \mathrm{C}\right)$ & $\mathrm{R}(\mathrm{K} \Omega)$ \\
\hline 0.0 & 30.9500 & 12.0 & 18.2370 & 24.0 & 10.4197 & 36.0 & 6.2498 & 48.0 & 3.8767 \\
\hline 1.0 & 29.4145 & 13.0 & 17.2099 & 25.0 & 9.9710 & 37.0 & 5.9976 & 49.0 & 3.7311 \\
\hline 2.0 & 27.9786 & 14.0 & 16.4123 & 26.0 & 9.5462 & 38.0 & 5.7592 & 50.0 & 3.5916 \\
\hline 3.0 & 26.6026 & 15.0 & 15.6644 & 27.0 & 9.1394 & 39.0 & 5.5299 & 51.0 & 3.4579 \\
\hline 4.0 & 25.3263 & 16.0 & 14.9565 & 28.0 & 8.7525 & 40.0 & 5.3106 & 52.0 & 3.3303 \\
\hline 5.0 & 24.1099 & 17.0 & 14.2785 & 29.0 & 8.4554 & 41.0 & 5.1032 & 53.0 & 3.2067 \\
\hline 6.0 & 22.9532 & 18.0 & 13.6403 & 30.0 & 8.0346 & 42.0 & 4.9037 & 54.0 & 3.0890 \\
\hline 7.0 & 21.8564 & 19.0 & 13.0321 & 31.0 & 7.7016 & 43.0 & 4.7123 & 55.0 & 2.9773 \\
\hline 8.0 & 20.8194 & 20.0 & 12.4538 & 32.0 & 7.3825 & 44.0 & 4.5308 & & \\
\hline 9.0 & 19.8423 & 21.0 & 11.9054 & 33.0 & 7.0774 & 45.0 & 4.3553 & & \\
\hline 10.0 & 18.9150 & 22.0 & 11.3869 & 34.0 & 6.7883 & 46.0 & 4.1898 & & \\
\hline 11.0 & 18.2370 & 23.0 & 10.8883 & 35.0 & 6.5131 & 47.0 & 4.0303 & & \\
\hline
\end{tabular}

Because the relationship between the sensor resistance $\mathrm{R}$ and the temperature $\mathrm{T}$ is nonlinear, so we choose the Close fitting toolbox of the matlab to obtain the function cures between $\mathrm{T}$ and $\mathrm{R}$. Their relationship is of the equation (1).

$$
\mathrm{T}=-0.004024 * \mathrm{R}^{\wedge} 3+0.277 * \mathrm{R}^{\wedge} 2-6.995 * \mathrm{R}+71.06
$$


In the actual calibration process, the corresponding parameters should be set up in the modification of the software. Through debugging, when the temperature is 25 degrees, the measured value of the temperature sensor is about $10 \mathrm{~K} \Omega$. Through the parameters of Table 1 we can draw the conclusion that: the fitting curve can meet the requirement of our design. The connection circuit of the temperature sensor can be seen in Fig 3.

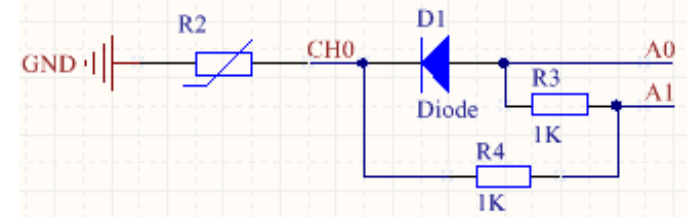

Fig 3. Circuit of the Temperature sensor

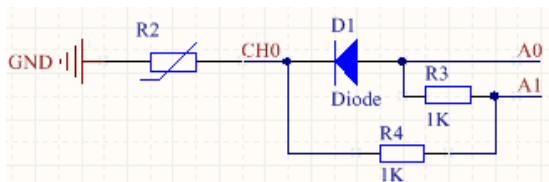

Fig 4. Circuit of the Humidity sensor

\subsection{The Choice of the Humidity Sensor.}

The selection of the humidity sensor is HR202L, it is also a two-wire sensor and convenient for us to put it on the diapers. It has a strong ability to avoid pollution. It can also keep stable by long-term using, while its price is low, has a high ratio and easy for people to get and use it.

The principle of the humidity sensor is: there is a film with a sense of wet material covered over the layer of the resistance substrate. When the water vapor in the air absorb on the sense of the wet film, the humidity sensor's electrical resistivity and resistance value will change, using the changeable character can measure the humidity. The connection circuit of the humidity sensor can be seen in Fig 4.

\subsection{The Constant-current Source Module.}

The reason using the constant-current source module can be seen as follows: to achieve the desired function, with the changing of the temperature, the resistance value of MF51-9.971K-3950-200L will change responsibility. By Ohm's law we can easily obtain the relative voltage value, then qualify it to the temperature value. More important is that the constant-current circuit can guarantee the environment of the system's circuit working stably. It is carried by LM334 chip.

Through experiment test, at the temperature of 25 degrees, the temperature sensor's resistance value is about 9.9--10K $\Omega$, it matches our practical requirements. This shows the design of constant-current source is successful for the detection system of diapers. The circuit of constant-current circuit can be seen in Fig 5.

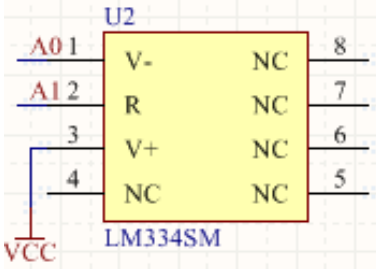

Fig 5. the circuit of the constant-current source

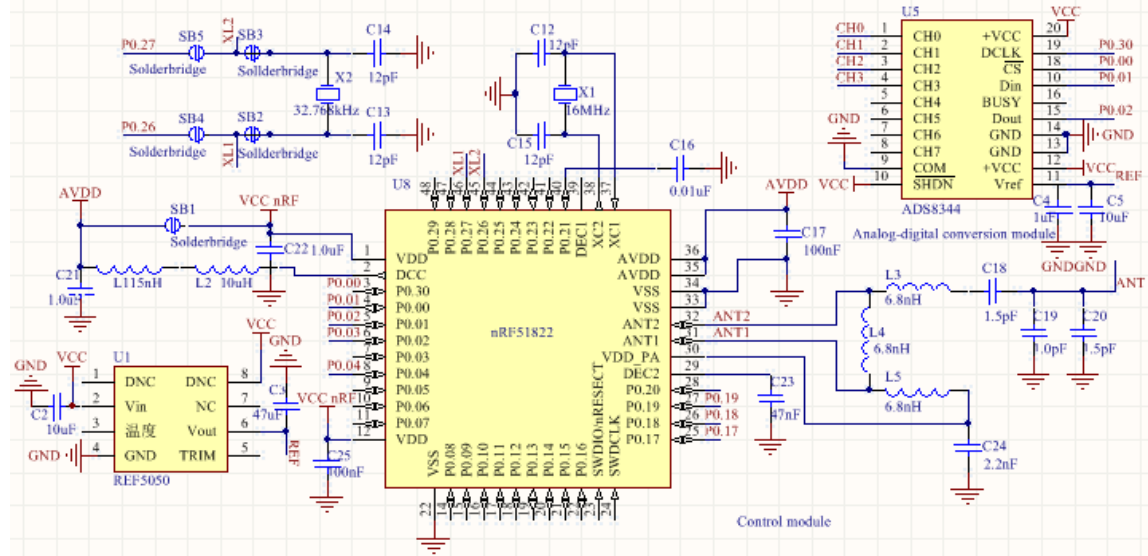

Fig 6 the circuit of the Analog-digital conversion module and Control module 


\subsection{Analog-digital Conversion Module and Control Module.}

The circuit can be seen in Fig 6.The control model is the single-chip of nRF51822, its small volume make it easy to be embedded in the clothing, and it has its own Bluetooth. The Analog-digital conversion is made of ADS8344 chip.

\subsection{The Software Procedure Design of the System}

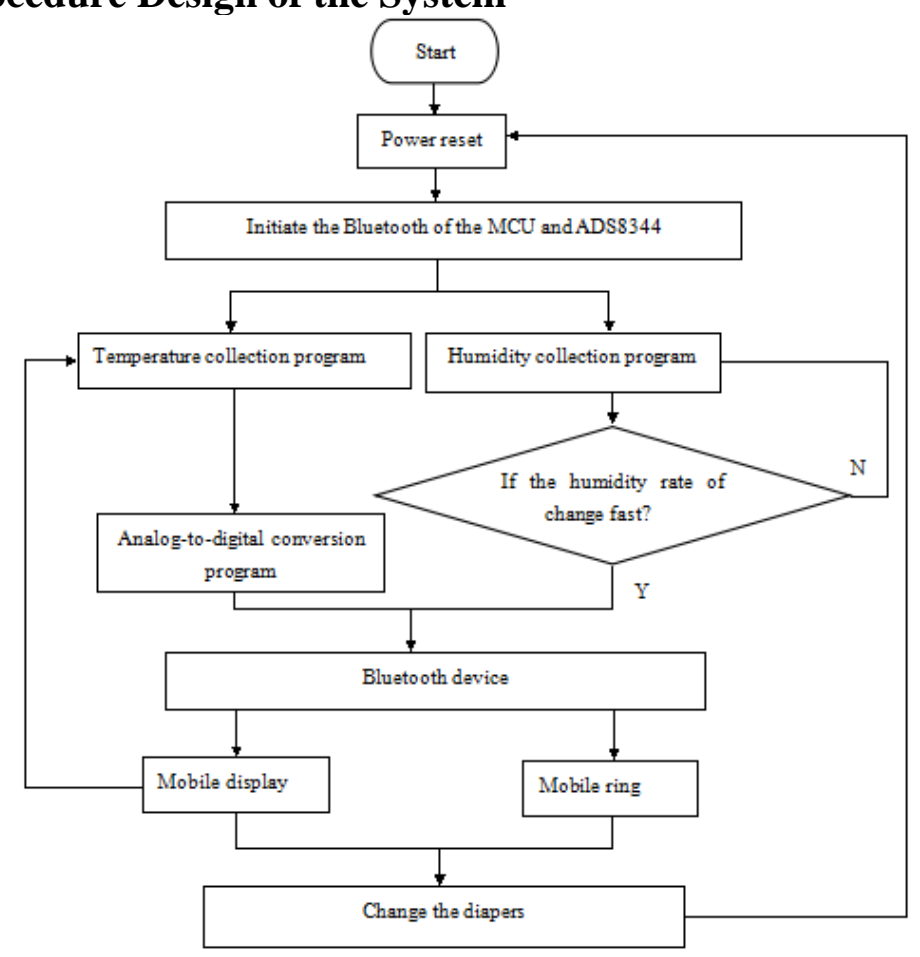

The software procedure of the system

\section{Summary}

After the completion of the electric system, we should also consider the combination of electric system and diapers. The overall comfort of the diapers cannot be changed, then it should be easy to be installed and disassembled. The system we design is a good example of the combination of electronic information technology and clothing industry. The design of diapers internal environment detection system is a new application which can bring many benefits to our life.

\section{References}

[1]Nakajima, Hiromasa1. Masaharu.Development of RFID antenna for detection of urination. [J]IEICE Transactions on Communications. v E96-B, n 9, p 2244-2250, September 2013

[2]Ng, Frency Sau-FunInformation and mothers' attitudes on diapers for babies[J]Journal of the Japan Research Association for Textile End-Uses, v 54, n 4, p 61-68, April 2013

[3]Galpothdeniya, Waduge Indika S. Ionic liquid-based optoelectronic sensor arrays for chemical detection.[J]RSC Advances, v 4, n 14, p 7225-7234, 2014 